\title{
The consequence of refreshing for access to nonselected items in young and older adults
}

\author{
Julie A. Higgins and Marcia K. Johnson \\ Yale University, New Haven, Connecticut
}

\begin{abstract}
We examined the effect of competition on briefly thinking of just-seen items. In Experiment 1, participants saw a set of either three related or three unrelated words and then read one of the words again (repeat) or thought briefly of one of the words (refresh). Participants read the set a second time, after which they either refreshed a second word from the set or read a new word. In comparison with reading a new word, response times were slower for refreshing the second item when participants had just refreshed than when they had just repeated the first item. This increase was larger for related words than for unrelated words and for older adults than for younger adults. In Experiment 2, a negative impact of refreshing was observed when participants repeated a different word from the set. The pattern of findings suggests that the negative impact of refreshing comes from increased competition from the refreshed item, rather than from inhibition of the nonrefreshed items.
\end{abstract}

According to the multiple-entry, modular memory (MEM; Johnson, 1992; Johnson \& Hirst, 1993) model of cognition, complex reflection such as planning, deciding, and organizing is made up of component processes such as retrieving information and noting relations between representations. For example, planning ahead may involve noting the relevance of current information to future goals and retrieving relevant memories of past events.

One of the simplest reflective processes is immediately thinking of information that was just experienced and whose representation is still active-refreshing (Johnson, 1992; Johnson \& Hirst, 1993). Refreshing can be thought of as an executive function of working memory (Baddeley, 1986; Baddeley \& Hitch, 1974) in that it is recruited to briefly maintain or manipulate information that is currently active (Blumenfeld \& Ranganath, 2006; D'Esposito et al., 1998). Refreshing has been proposed to be a mechanism that foregrounds the representation of a just-experienced event (either perceptual or reflective) with respect to other representations that are currently active (Johnson et al., 2005; Raye, Johnson, Mitchell, Greene, \& Johnson, 2007). According to this view, refreshing is a mechanism by which items can be brought into the focus of attention (Cowan, 1999; Oberauer \& Kliegl, 2006). For example, in a search of working memory (Sternberg, 1966), refreshing might be a mechanism by which individual representations from the set are foregrounded for the purpose of comparison with the probe item.

Refreshing can be distinguished operationally from other component processes of reflection (Johnson, Raye, Mitchell, Greene, \& Anderson, 2003; Raye et al., 2007). For example, whereas refreshing typically operates on individual items over very brief intervals, rehearsing typically maintains multiple items over longer intervals. As was noted above, some process such as refreshing is logically needed to select an item from a set of items that are actively being rehearsed. Refreshing may also be involved in the updating of items in working memory (Bjork, 1978; Morris \& Jones, 1990; Roth \& Courtney, 2007), in that refreshing might help foreground the representation of the "new" target, privileging it relative to the representations of older targets that are still active. Refreshing is also distinct from processes that revive information from long-term memory (e.g., reactivating, retrieving). At the same time, a cue may be refreshed during recall, and this foregrounding of the recall cue may help to reactivate representations in long-term memory or facilitate the initiation of more strategic retrieval of additional cues and the target. For example, during a category-generation task (Blaxton \& Neely, 1983; Loftus, 1973), the letter cue may be refreshed, which helps reactivation and evaluation of an appropriate exemplar representation.

Johnson and colleagues (e.g., Johnson et al., 2005) have investigated refreshing by cuing participants to think immediately of an item that they have just experienced perceptually. In one study (Johnson, Reeder, Raye, \& Mitchell, 2002), participants saw a word, followed by the same word, a new word, or a dot cue. Participants read each word aloud, and when they saw the dot, they thought of (i.e., refreshed) the word that they had just seen and said that word aloud. Response times (RTs) for refreshing a word were significantly longer than RTs for reading the word again or for reading a new word, reflecting the additional time that is necessary to refresh an item that is no longer perceptually present. Refreshed items were more

J. A. Higgins, julie.higgins@yale.edu 
memorable on a later recognition test than were items that were read once or items that were read twice.

Refreshing may play an especially important role in selection among active representations. That is, information (e.g., a word) rarely occurs in isolation but instead is part of a more complex experience. A study investigating selective refreshing compared participants' RTs for refreshing one of three potential items and their RTs for refreshing one item that was shown alone (Raye, Mitchell, Reeder, Greene, \& Johnson, 2008). Relative to repeat and read conditions, participants were slower to refresh when selection was required than when it was not. One hypothesis is that selective refreshing involves resolving competition from active distractor items in order to select the target item. This idea is consistent with neuroimaging results showing that, in comparison with refreshing one item shown alone, selectively refreshing one item from a set of three is associated with greater activation of the anterior cingulate cortex (Johnson et al., 2005, Experiment 5), an area that is thought to be involved in conflict detection (Botvinick, Nystrom, Fissell, Carter, \& Cohen, 1999).

Previous studies of selective refreshing have not examined the "fate" of the nonselected items. Does refreshing an item from a set of active items affect the accessibility of the other items in the set? That is, does refreshing from currently active representations produce negative effects that are similar to the output interference (McGeoch, 1936; Tulving \& Arbuckle, 1963) or retrieval-induced forgetting (Anderson, Bjork, \& Bjork, 1994) that is seen in accessing information from long-term memory? In the present study, we investigated the effect of selectively refreshing on subsequent reflective (Experiment 1) and perceptual (Experiment 2) processing of the nonrefreshed items. The degree of competition was manipulated using sets that contained either related or unrelated words. Because related sets contained both semantically similar and episodically similar items, they should have resulted in more competition than did unrelated sets, in which only episodic competition was present. In Experiment 1, we observed that selective refreshing had the negative impact of reducing accessibility of the nonselected items during subsequent reflective processing, especially under conditions of high competition (i.e., related trials). Older adults showed a larger negative impact of refreshing than did young adults, which, given age-related deficits in inhibitory mechanisms (Hasher, Lustig, \& Zacks, 2007; Hasher \& Zacks, 1988), suggests that this reduced accessibility did not arise from inhibition of the nonrefreshed items. In Experiment 2, we observed a negative impact of refreshing on subsequent perceptual processing that was equal for related and unrelated items.

\section{EXPERIMENT 1}

In Experiment 1, a trial consisted of two tasks. In Task 1, participants saw and read aloud three related or unrelated words, after which they saw and read aloud one of the three words that was presented again (repeat), or thought of and said aloud the word that had appeared previously in a cue's location (refresh). In Task 2, participants saw and read aloud the word set from Task 1 a second time, after which they either refreshed a different item from the set or read a new word that was presented on the screen (read). Thus, we tested whether selective refreshing during Task 1 influenced subsequent refreshing of nonselected items (i.e., during Task 2). Specifically, we predicted that selective refreshing might have the negative consequence of reducing the accessibility of the nonrefreshed items, particularly for related trials. This reduced accessibility would be reflected in longer RTs for refreshing an item on Task 2 when one has just refreshed than when one has just repeated an item from the same set as that on Task 1. In contrast, refreshing would have less, or no, influence on subsequent processing of a new item that was not present at the time of refreshing. Hence, we expected that RTs for reading a new item on Task 2 would be influenced less than RTs for refreshing on Task 2 by the nature of the processing on Task 1.

In addition, we tested whether the negative impact of selective refreshing results from inhibition of the nonrefreshed items during Task 1, which reduces their accessibility during Task 2. To this end, in Experiment 1C, we investigated the effect of refreshing on subsequent refreshing in older adults (OAs). Aging is associated with inhibitory deficits (Hasher et al., 2007; Hasher \& Zacks, 1988). If the negative impact of prior selective refreshing is due to inhibition, OAs will show less of an effect than will young adults (YAs), because OAs will inhibit the nontarget items less efficiently while refreshing on Task 1.

Experiments 1A and 1B tested YAs and had similar designs with one exception. In Experiment 1A, filler trials were also included. Filler trials consisted of one (single) presentation of a three-word set, after which participants repeated, refreshed, or read a new word. Experiment 1C tested OAs, using the same methods and procedure as those in Experiment 1B, and it was run concurrently with Experiment 1B.

\section{Method}

\section{Participants}

YAs in Experiments 1A and 1B were recruited from the Yale community, and they received payment or course credit for their participation. OAs in Experiment 1C were recruited from the New Haven community, and they received payment for their participation.

Experiment 1A. Participants were 30 YAs ( 15 male, 15 female; mean age $=19.03$ years, $S D=1.19$, range $=18-22$ years). Participants had an average of 13.83 years $(S D=.99)$ of education and scored an average of $23.55(S D=3.78)$ out of a possible 30 on an abbreviated version of the verbal subscale of the Wechsler Adult Intelligence Scale-Revised (WAIS-R; Wechsler, 1987).

Experiment 1B. Participants were 24 YAs ( 9 male, 15 female; mean age $=20.21$ years, $S D=1.93$, range $=18-25$ years $)$. Participants had an average of 14.21 years $(S D=1.35)$ of education and an average score of $22.92(S D=3.54)$ on the WAIS-R.

Experiment 1C. Participants were 24 OAs (6 male, 18 female; mean age $=72.60$ years, $S D=6.22$, range $=60-85$ years $)$. Participants had an average of 17.38 years $(S D=1.47)$ of education and scored an average of $22.08(S D=4.62)$ on the WAIS-R. OAs demonstrated high levels of cognitive function, evidenced by an average Mini-Mental State Examination (Folstein, Folstein, \& McHugh, $1975)$ score of $28.54(S D=1.14)$ out of a possible 30 . As compared with YAs (collapsed across Experiments 1A and 1B), OAs had significantly more years of education (YAs, $M=14.00)[t(76)=$ 
10.88 , Cohen's $d=2.67]$, but scored comparably on the WAIS-R (YAs, $M=23.27$ ) $[t(76)=1.22, p=.23]$.

\section{Apparatus}

Participants were seated at a distance of $30-40 \mathrm{~cm}$ from a computer monitor, with their heads centered vertically and horizontally with respect to the monitor. Verbal responses were recorded using a head-mounted microphone that was interfaced with a PsyScope button box. PsyScope software was used to control stimulus presentation and the recording of RTs.

\section{Materials}

Word stimuli for all experiments were low-, medium-, and highranking exemplars of semantic categories (Battig \& Montague, 1969; Shapiro \& Palermo, 1970). Four exemplars were chosen from 96 different semantic categories for a total stimulus set of 384 words. Each category appeared once on each stimulus list. For Experiment 1A, the stimulus set had a word frequency (Kučera \& Francis, 1967), syllable length, and letter length of 29.73, 2.04, and 6.29, respectively. Minor substitutions to the stimulus set for Experiments 1B and $1 \mathrm{C}$ resulted in an overall word frequency, syllable length, and letter length of $30.92,1.99$, and 6.18 , respectively.

Three of the four exemplars were chosen in such a way that they included one high-ranking (e.g., soda), one medium-ranking (e.g., coffee), and one low-ranking (e.g., lemonade) exemplar from the category. Two of these items were designated as the critical items for Task 1 (e.g., lemonade) and Task 2 (e.g., soda). The Task 1 and Task 2 targets were never the same word (hence, never the same rank). The fourth exemplar (e.g., water) functioned as a filler item for the Task 2 read task. As is illustrated in Figure 1, the read filler replaced the critical item in the word set (therefore rendering the critical item a new word during Task 2). This was done to control for item effects across all task types when critical RTs for saying the word aloud were measured. Read filler items were chosen to be of the same rank as the items that they replaced.

\section{Design}

Each experiment used a 2 (Task 2: refresh, read) $\times 2$ (Task 1 : refresh, repeat) $\times 2$ (semantic relatedness: unrelated, related) within-subjects design. There were four possible Task 1-Task 2 combinations: refresh-refresh, refresh-read, repeat-refresh, and repeat-read. Half of all trials contained related items, and the other half contained unrelated items. Within a stimulus list, trial order was pseudorandomized in such a way that no more than three instances of any task or trial type appeared consecutively (e.g., no more than three trials in a row occurred in which Task 1 was a refresh, or in which the items were related, etc.). Participants completed a practice session containing one trial of each type prior to performing the main task.

Experiment 1A. There were 16 instances (half unrelated, half related) of each Task 1-Task 2 combination, for a total of 64 critical trials. In addition to critical trials, 32 filler trials (half unrelated, half related) were included. On a filler trial, the word set was presented one time, followed approximately one third of the time by a repeat task, one third of the time by a refresh task, and one third of the time by a read task. Filler trials were included to prevent an expectation on the part of the participants that they would always be required to process the set a second time. Such an expectation might have engaged additional processes in anticipation of later task demands, which could have obscured our main effect of interest (i.e., the effect of selectively refreshing on subsequent processing of the nonrefreshed items). RTs from filler trials were not analyzed. Across different lists, critical Task 2 items were rotated through each of the four possible critical trials and appeared twice as filler items, resulting in a total of six different stimulus lists that were rotated across participants. For Task 1, one of the two items that was not

Related Trials

Task 1

Task 2

\begin{tabular}{|c|c|c|c|}
\hline \multicolumn{3}{|c|}{ Refresh (or Repeat) } & Refresh \\
\hline $\begin{array}{l}\text { Coffee } \\
\text { Lemonade } \\
\text { Soda }\end{array}$ & - (or Lemonade $)$ & $\begin{array}{l}\text { Coffee } \\
\text { Lemonade } \\
\text { Soda }\end{array}$ & - \\
\hline \multicolumn{3}{|c|}{ Refresh (or Repeat) } & Read \\
\hline $\begin{array}{l}\text { Coffee } \\
\text { Lemonade } \\
\text { Water }\end{array}$ & - $($ or Lemonade $)$ & $\begin{array}{l}\text { Coffee } \\
\text { Lemonade } \\
\text { Water }\end{array}$ & Soda \\
\hline
\end{tabular}

Unrelated Trials

\begin{tabular}{|c|c|c|c|}
\hline \multicolumn{3}{|c|}{ Refresh (or Repeat) } & Refresh \\
\hline $\begin{array}{l}\text { Hood } \\
\text { Forgery } \\
\text { Soda }\end{array}$ & - $($ or Forgery $)$ & $\begin{array}{l}\text { Hood } \\
\text { Forgery } \\
\text { Soda }\end{array}$ & • \\
\hline \multicolumn{3}{|c|}{ Refresh (or Repeat) } & Read \\
\hline $\begin{array}{l}\text { Hood } \\
\text { Forgery } \\
\text { Film }\end{array}$ & - $($ or Forgery $)$ & $\begin{array}{l}\text { Hood } \\
\text { Forgery } \\
\text { Film }\end{array}$ & Soda \\
\hline
\end{tabular}

Figure 1. Sample trials in Experiment 1. The trial started with the presentation of the three-word set. Participants read aloud three words, starting with the top word. After the set disappeared, participants either refreshed or repeated one of the words (Task 1). Participants saw and read aloud the word set a second time, after which they either refreshed an item from the set or read a new word (Task 2). The Task 1 target and Task 2 target were never the same item. To equate target items across the tasks, a filler word was substituted for one word in the three-word set for trials in which Task 2 was a "read." 
designated as a critical item on Task 2 was randomly assigned to be either a refresh or a repeat item on Task 1. Location and rank of the Task 1 and Task 2 targets were distributed in such a way that, across all trials, the target appeared in equal proportions in the top, middle, or bottom location, and was of high, medium, or low rank in equal proportions.

Experiments 1B and 1C. There were 24 trials (half unrelated, half related) of each Task 1-Task 2 combination, for a total of 96 critical trials. No filler trials were included, which allowed us to increase the number of critical trials. Critical items on Task 1 were rotated across both types of tasks in Task 1 (i.e., refresh and repeat). Since Task 2 target items were also rotated across all types of Task 2 (i.e., refresh-unrelated, refresh-related, read-unrelated, read-related), this resulted in a total of eight different stimulus lists that were rotated across participants. The location and rank of the Task 1 and Task 2 targets, as well as Task 1-Task 2 location and rank combinations (e.g., top-bottom combinations, high-low combinations) were roughly equated within each condition in such a way that across the stimulus list each combination appeared an equal number of times.

\section{Trial Presentation}

A modified version of the selective-refresh paradigm (Johnson et al., 2005, Experiment 5) was used, in which the three-word set contained either all related or all unrelated words. Each critical trial began with three boxes that were presented in a single column in the middle of the screen, with one word inside each box. These words were either semantically related or semantically unrelated to each other, and they remained on the screen for 2,250 msec. Participants were instructed to read the words aloud as quickly but as accurately as possible. Following a 500-msec interval, one of two types of task occurred (Task 1). In a Task 1 refresh task, a dot cue appeared in one of the locations that was previously occupied by a word. Participants were instructed to think of the word that had just appeared in the dot's location and to say that word aloud. In a Task 1 repeat task, one of the original three words was presented again in the same location in which it had appeared as part of the set. Participants were instructed to read the re-presented word aloud. The dot or word remained on the screen for $1,500 \mathrm{msec}$. Following a 500 -msec interstimulus interval, the entire word set reappeared on the screen for $2,250 \mathrm{msec}$. Participants were instructed to read the word set aloud. Following a 500-msec interval, one of two types of task occurred (Task 2). In a Task 2 refresh task, a dot cue appeared in one of the boxes. Participants thought of and said aloud the word that had just previously appeared in the dot's location. In a Task 2 read task, a new word appeared in one of the boxes, and the participants read that word aloud. During a 1,500 -msec intertrial interval, only the three boxes remained on the screen. Participants were instructed to respond as quickly but as accurately as possible at all times.

\section{Results}

RTs for refreshing or reading aloud the target words on Task 2 were recorded and analyzed. ${ }^{1}$ In all experiments, unless otherwise noted, the alpha level was set to .05 for all statistical tests, and all $t$ tests were two-tailed.

\section{Errors}

Errors were classified into two types: response errors and other errors. Response errors included trials in which participants failed to respond, stuttered, or responded with an incorrect word, or in which another vocalization (e.g., "um") preceded the correct response (and thus triggered the microphone inaccurately). Other errors included trials in which an extraneous sound (e.g., a sneeze) occurred, an RT shorter than a minimum value (i.e., more than three standard deviations below the group mean) occurred, or the microphone failed to trigger because of technical problems.

The average proportions of Task 2 response (and other) errors in Experiments 1A, 1B, and 1C, respectively, were as follows: refresh-refresh-unrelated $=.02(.00)$, $.03(.01), .08(.08)$; refresh-refresh-related $=.03(.01)$, $.03(.02), .06(.07)$; refresh-read-unrelated $=.02(.01)$, $.02(.01), .02(.05)$; refresh-read-related $=.00(.03), .01$ $(.00), .00(.04)$; repeat-refresh-unrelated $=.01(.02), .02$ (.00), $.03(.04)$; repeat-refresh-related $=.02(.02), .02$ (.01), .02 (.04); repeat-read-unrelated $=.01(.00), .01$ $(.02), .01(.02)$; repeat-read-related $=.01(.01), .00(.01)$, $.01(.01)$.

As would be expected from previous refresh studies (Johnson et al., 2002), therefore, response accuracy was high, and statistical analyses of the response error rates showed no evidence of a speed-accuracy trade-off in any of the experiments. Error RTs were removed from further analysis.

\section{RTs}

To investigate whether the presence of filler trials affected performance, RTs for refreshing or reading on Task 2 for YAs in Experiments 1A and 1B were submitted to a 2 (experiment: 1A, 1B) $\times 2$ (Task 2: refresh, read) $\times 2$ (Task 1: refresh, repeat) $\times 2$ (semantic relatedness: unrelated, related) ANOVA. Experiment was a between-subjects factor, and Task 2, Task 1, and semantic relatedness were within-subjects factors. There was a main effect of experiment, with slower RTs in Experiment 1A $(686 \mathrm{msec})$ than in Experiment 1B $(649 \mathrm{msec})$ $\left[F(1,52)=4.19, M S_{\mathrm{e}}=35,137.63, \eta_{\mathrm{p}}^{2}=.074\right]$. Because experiment did not interact significantly with any of the other factors, Task 2 RTs for YAs were collapsed across experiment in the subsequent analyses.

RTs for refreshing or reading a word on Task 2 (see Table 1A) were submitted to a 2 (age: YA, OA) $\times 2$ (Task 2: refresh, read) $\times 2$ (Task 1: refresh, repeat $) \times 2$ (semantic relatedness: unrelated, related) ANOVA. Age was a between-subjects factor, and Task 2, Task 1, and semantic relatedness were within-subjects factors. There was a significant main effect of age, with slower RTs for OAs $(837 \mathrm{msec})$ than for YAs $(670 \mathrm{msec})[F(1,76)=$ $\left.90.19, M S_{\mathrm{e}}=41,366.27, \eta_{\mathrm{p}}^{2}=.54\right]$. There were also significant main effects of Task 2, with slower RTs for refreshing a word $(788 \mathrm{msec})$ than for reading a new word $(720 \mathrm{msec})\left[F(1,76)=38.05, M S_{\mathrm{e}}=16,050.49, \eta_{\mathrm{p}}^{2}=\right.$ .33 ], and of semantic relatedness, with faster RTs on related trials $(745 \mathrm{msec})$ than on unrelated trials $(762 \mathrm{msec})$ $\left[F(1,76)=17.48, M S_{\mathrm{e}}=2,255.15, \eta_{\mathrm{p}}^{2}=.19\right]$. Finally, there was a significant main effect of Task 1 , with longer RTs for responding on Task 2 when participants had just refreshed $(765 \mathrm{msec})$ on Task 1 than when they had just repeated $(742 \mathrm{msec})$ on Task $1\left[F(1,76)=24.11, M S_{\mathrm{e}}=\right.$ $\left.2,948.33, \eta_{\mathrm{p}}^{2}=.24\right]$.

The following two-way interactions were significant: age $\times$ Task $1\left[F(1,76)=8.82, M S_{\mathrm{e}}=2,948.33, \eta_{\mathrm{p}}^{2}=\right.$ $.10]$; age $\times$ Task $2\left[F(1,76)=7.63, M S_{\mathrm{e}}=16,050.49\right.$, $\left.\eta_{\mathrm{p}}^{2}=.091\right]$; Task $1 \times$ Task $2\left[F(1,76)=23.16, M S_{\mathrm{e}}=\right.$ $\left.3,499.74, \eta_{\mathrm{p}}^{2}=.23\right]$; and Task $2 \times$ semantic relatedness 
Table 1

Task 2 Response Times (RTs, in Milliseconds) for Experiments 1 and 2

\begin{tabular}{|c|c|c|c|c|c|c|c|c|}
\hline & \multicolumn{8}{|c|}{ Experiment 1} \\
\hline & \multicolumn{2}{|c|}{ RT } & \multirow[b]{2}{*}{ Diff } & \multirow[b]{2}{*}{$95 \% \mathrm{CI}$} & \multicolumn{2}{|c|}{ RT } & \multirow[b]{2}{*}{ Diff } & \multirow[b]{2}{*}{$95 \% \mathrm{CI}$} \\
\hline & Ref-Ref & Rep-Ref & & & Ref-Rd & Rep-Rd & & \\
\hline \multicolumn{9}{|l|}{ Young Adults } \\
\hline Unrelated & 691 & 691 & 0 & $-23,24$ & 665 & 657 & 8 & $-4,20$ \\
\hline Related & 700 & 672 & 28 & 7,50 & 642 & 642 & 0 & $-13,12$ \\
\hline \multicolumn{9}{|l|}{ Older Adults } \\
\hline Unrelated & 927 & 861 & 66 & 22,111 & 805 & 802 & & $-30,36$ \\
\hline \multirow[t]{4}{*}{ Related } & 927 & 831 & 96 & 46,147 & 764 & 781 & -17 & $-36,1$ \\
\hline & \multicolumn{8}{|c|}{ Experiment 2} \\
\hline & \multicolumn{2}{|c|}{ RT } & & & \multicolumn{2}{|c|}{ RT } & & \\
\hline & Ref-Rep & Rep-Rep & Diff & $95 \% \mathrm{CI}$ & Ref-Rd & Rep-Rd & Diff & $95 \% \mathrm{CI}$ \\
\hline \multicolumn{9}{|l|}{ Young Adults } \\
\hline Unrelated & 608 & 593 & 15 & 3,28 & 690 & 693 & -3 & $-23,16$ \\
\hline Related & 590 & 575 & 15 & 3,27 & 664 & 656 & 8 & $-8,23$ \\
\hline
\end{tabular}

Note-In Experiment 1, RTs for refreshing on Task 2 were slower when participants had just refreshed on Task 1 than when they had just repeated on Task 1. This mean increase was larger for related than for unrelated trials and for older than for young adults. In Experiment 2, RTs for repeating on Task 2 were slower when participants had just refreshed on Task 1 than when they had just repeated on Task 1 . This mean increase was equal for related and unrelated trials. Ref-Ref $=$ RTs for refreshing on Task 2 having just refreshed on Task 1. Rep-Ref $=$ RTs for refreshing on Task 2 having just repeated on Task 1. Ref-Rd $=$ RTs for reading on Task 2 having just refreshed on Task 1. Rep-Rd $=$ RTs for reading on Task 2 having just repeated on Task 1. Ref-Rep $=$ RTs for repeating on Task 2 having just refreshed on Task 1 . Rep-Rep $=$ RTs for repeating on Task 2 having just repeated on Task 1. Diff = mean increase in RTs on Task 2 having just refreshed versus having just repeated on Task $1 . \mathrm{CI}=$ confidence interval of the mean increase.

$\left[F(1,76)=4.20, M S_{\mathrm{e}}=1,837.75, \eta_{\mathrm{p}}^{2}=.052\right]$. These interactions were qualified by the presence of 2 three-way interactions.

There was a significant Task $2 \times$ Task $1 \times$ semantic relatedness interaction $\left[F(1,76)=7.79, M S_{\mathrm{e}}=2,010.60\right.$, $\left.\eta_{\mathrm{p}}^{2}=.093\right]$. As compared with having just repeated on Task 1 , having just refreshed significantly increased RTs for refreshing on Task 2 for related $[t(77)=4.44$, Cohen's $d=0.50]$ and unrelated $[t(77)=1.91, p=.06$, Cohen's $d=0.22]$ trials; however, this increase was larger for related trials $(M=49 \mathrm{msec})$ than for unrelated trials $(M=$ $21 \mathrm{msec})[t(77)=2.15$, Cohen's $d=0.24]$. Task 2 RTs for reading both related and unrelated words did not differ as a function of Task 1 . The mean increase for related words was $-6 \operatorname{msec}[t(77)=-1.09, p=.28]$, and the mean increase for unrelated words was $7 \mathrm{msec}[t(77)=$ $1.05, p=.30]$.

There was a significant age $\times$ Task $2 \times$ Task 1 interaction $\left[F(1,76)=14.50, M S_{\mathrm{e}}=3,499.74, \eta_{\mathrm{p}}^{2}=.16\right]$. As compared with having just repeated on Task 1 , having just refreshed increased RTs for subsequently refreshing [mean increase $=35 \mathrm{msec}, t(77)=3.98$, Cohen's $d=$ $0.45]$, but not for reading a new item [mean increase $=$ $1 \mathrm{msec}[t(77)=0.14, p=.89]$, on Task 2 for both age groups; however, this increase in RTs for refreshing on Task 2 was disproportionately larger in OAs (mean increase $=81 \mathrm{msec}$ ) than in YAs (mean increase $=14 \mathrm{msec}$ ) $[t(76)=3.83$, Cohen's $d=0.94]$.

No other interactions were significant: [age $\times$ semantic relatedness, $F(1,76)=1.74, M S_{\mathrm{e}}=2,255.15, p=.19$; Task $1 \times$ semantic relatedness, $F(1,76)=0.63, M S_{\mathrm{e}}=$ 2,673.72, $p=.43$; age $\times$ Task $1 \times$ semantic relatedness, $F(1,76)=0.07, M S_{\mathrm{e}}=2,673.72, p=.79 ;$ age $\times$ Task $2 \times$ semantic relatedness, $F(1,76)=0.034, M S_{\mathrm{e}}=1,837.75$, $p=.85$; age $\times$ Task $2 \times$ Task $1 \times$ semantic relatedness, $\left.F(1,76)=0.22, M S_{\mathrm{e}}=2,010.60, p=.64\right] .^{2}$

\section{Discussion}

In Experiment 1, YA and OA participants read aloud a set of three words and then either refreshed or repeated one of the words (Task 1). Participants then saw the word set a second time, after which they either refreshed a second word from the set or read a new word (Task 2). Both age groups were slower to refresh on Task 2 when they had just refreshed on Task 1 than when they had just repeated on Task 1, suggesting that briefly thinking of one item from a set has the negative consequence of reducing accessibility of the nonrefreshed items. This increase in RTs was greater when the items were related. Although they are not semantically similar to each other, unrelated items - by virtue of being presented in a set-can be considered episodically similar and can thus also be sources of competition. Related sets would be expected to produce a greater degree of competition (both episodic and semantic). The negative consequence of selective refreshing, therefore, depends upon the amount and/or type of competition that is present. The finding that the nature of prior processing (refreshing vs. repeating) did not influence RTs for reading a new item on Task 2 indicates that the negative impact of refreshing is greater for (or restricted to) items that were present at the time of refreshing.

If refreshing on Task 1 had resulted in inhibition of the nonrefreshed items, OAs might have been expected to show less of a negative impact of selective refreshing on subsequent refreshing of nonselected items, given that aging has been associated with inhibitory deficits (Hasher 
et al., 2007; Hasher \& Zacks, 1988). They showed the opposite pattern, however. OAs showed a larger negative effect of prior selective refreshing relative to YAs. This finding does not support the idea that selective refreshing produces inhibition of the nonselected items. If not inhibition, what causes the reduced accessibility of the nonselected items? An alternate possibility is that reduced accessibility of nonselected items is a consequence of enhanced activation of the refreshed item. According to this enhanced-activation account, refreshing on Task 1 enhances the activation of the target item and does not inhibit the activation of the nontarget items. This highly activated item (i.e., the Task 1 target) becomes a source of strong competition on Task 2, when it becomes a distractor item. Given that aging has been associated with increased vulnerability to interference (Hedden \& Park, 2001), the present finding of a larger negative impact of prior refreshing in OAs than in YAs is consistent with an age-related vulnerability to the presence of a highly active competitor (i.e., the prior refresh target). It is unlikely that OAs are enhancing targets to a greater degree than are YAs during refreshing; rather, they are more sensitive to interference from the enhanced target, even if this enhancement is relatively less than that in young adults. This enhanced-activation account is also consistent with our finding that a larger negative impact was observed for related trials than for unrelated trials. Because related items are presumably more active than unrelated items initially (due to shared semantic features), an enhanced related Task 1 target item provides even greater competition when it becomes a distractor on Task 2 than does an unrelated Task 1 target item. For additional analyses that are relevant to an inhibition-enhancement versus a targetenhancement account of the negative impact of refreshing on the nonselected items, see the Appendix.

\section{EXPERIMENT 2}

In Experiment 2, we tested the specificity of the negative impact of refreshing. Does prior refreshing from a set of items impair only subsequent reflective access to the nonrefreshed items, or is subsequent perceptual processing of the nonrefreshed items similarly impaired? The first outcome would be consistent with a segregation of reflective and perceptual representations. However, Yi, Turk-Browne, Chun, and Johnson (2008) have shown that refreshing an item affects the subsequent perceptual processing of that item. In the present experiment, we asked whether refreshing affects subsequent perceptual processing of the nonselected items as well. If so, it would provide further evidence of an interaction between the reflective and perceptual systems. To investigate these possibilities, we ran a modified version of Experiment 1B in which participants refreshed or repeated after the first presentation of the word set and then repeated or read a new word after the second presentation of the set. If prior refreshing only impairs subsequent reflective processing, we would not expect to observe a negative impact of prior refreshing on subsequent repeating. If, however, prior refreshing does impair subsequent perceptual processing of the nonrefreshed items, RTs for repeating on Task 2 should be slower when participants have just refreshed on Task 1 than when they have just repeated on Task 1 .

\section{Method}

\section{Participants}

Participants were 16 YAs ( 4 male, 12 female; mean age $=19.56$ years, $S D=1.59$, range $=18-23$ years) who were recruited as described in Experiment 1. Participants had an average of 13.19 years $(S D=1.38)$ of education and scored an average of $24.50(S D=2.63)$ out of a possible 30 on the vocabulary subscale of the WAIS-R.

\section{Apparatus, Materials, and Design}

Apparatus, materials, and design were similar to those in Experiment 1B, except that Task 2 refresh trials were replaced with Task 2 repeat trials; hence, the design of Experiment 2 was a 2 (Task 2: repeat, read $) \times 2$ (Task 1: refresh, repeat $) \times 2$ (semantic relatedness: unrelated, related) within-subjects design.

\section{Results}

RTs for saying the target words aloud (see Table 1B) on Task 2 were recorded and analyzed. ${ }^{3}$

\section{Errors}

The average proportions of Task 2 response (and other) errors by trial type were as follows: refreshrepeat-unrelated $=.00(.03)$; refresh-repeat-related $=$ $.01(.01)$; refresh-read-unrelated $=.02(.01)$; refreshread-related $=.02(.01)$; repeat-repeat-unrelated $=.01$ $(.01)$; repeat-repeat-related $=.00(.01)$; repeat-readunrelated $=.01(.01)$; repeat-read-related $=.03(.00)$. Statistical analyses of the response error rates showed no evidence of a speed-accuracy trade-off. Error RTs were removed from further analysis.

\section{RTs}

RTs for repeating or reading on Task 2 were submitted to a 2 (Task 2: repeat, read) $\times 2$ (Task 1: refresh, repeat $) \times$ 2 (semantic relatedness: unrelated, related) ANOVA. There was a significant main effect of Task 2 , with slower RTs for reading a new word $(676 \mathrm{msec})$ than for repeating a word $(591 \mathrm{msec})\left[F(1,15)=124.03, M S_{\mathrm{e}}=1,837.48\right.$, $\left.\eta_{\mathrm{p}}^{2}=.89\right]$. There was also a main effect of semantic relatedness, with faster RTs on related trials $(621 \mathrm{msec})$ than on unrelated trials $(646 \mathrm{msec})\left[F(1,15)=19.29, M S_{\mathrm{e}}=\right.$ $\left.1,009.78, \eta_{\mathrm{p}}^{2}=.56\right]$. Finally, there was a significant main effect of Task 1, with slower RTs on Task 2 when participants had just refreshed on Task $1(638 \mathrm{msec})$ than when they had just repeated on Task $1(629 \mathrm{msec})[F(1,15)=$ $\left.8.80, M S_{\mathrm{e}}=275.59, \eta_{\mathrm{p}}^{2}=.37\right]$.

There was a marginally significant Task $2 \times$ semantic relatedness interaction $\left[F(1,15)=4.40, M S_{\mathrm{e}}=302.57\right.$, $\left.p<.06, \eta_{\mathrm{p}}^{2}=.23\right]$. Although RTs were faster on related trials than on unrelated trials for both reading a new word (unrelated $=691 \mathrm{msec}$; related $=660 \mathrm{msec}$ ) and repeating a word (unrelated $=600 \mathrm{msec}$; related $=582 \mathrm{msec}$ ), this relatedness benefit was larger for reading (mean difference $=31 \mathrm{msec}$ ) than for repeating (mean difference $=$ $18 \mathrm{msec})[t(15)=2.10, p=.053$, Cohen's $d=0.52]$.

The Task $2 \times$ Task $1\left[F(1,15)=2.54, M S_{\mathrm{e}}=534.87\right.$, $p=.13]$ and the Task $2 \times$ Task $1 \times$ semantic relatedness 
$\left[F(1,15)=0.54, M S_{\mathrm{e}}=476.51, p=.47\right]$ interactions did not approach significance. Given that the effects of prior processing were of a priori interest, however, planned contrasts were performed to examine the effect of Task 1 on Task 2 for unrelated and related trials. RTs for repeating were significantly slower when participants had just refreshed than when they had just repeated for both unrelated trials (mean difference $=15 \mathrm{msec})[t(15)=2.66$, Cohen's $d=0.66]$ and related trials (mean difference $=15 \mathrm{msec}$ ) $[t(15)=2.69$, Cohen's $d=0.67)$. In contrast, RTs for reading on Task 2 were not significantly influenced by the nature of Task 1 for either unrelated [ $-3 \mathrm{msec} ; t(15)=$ $-0.36, p=.73]$ or related [8 msec; $t(15)=1.07, p=$ $.30]$ trials.

\section{Discussion}

In Experiment 2, participants read aloud a set of three words and then either refreshed or repeated one of the words (Task 1). Participants then saw the word set a second time, after which they either repeated a second word or read a new word (Task 2). Participants were slower to repeat an item on Task 2 when they had just refreshed on Task 1 than when they had just repeated on Task 1. This suggests that the negative impact of refreshing on subsequent refreshing that was found in Experiment 1 was not due simply to the fact that the same type of task was performed on the same set of items. Instead, reduced accessibility of the nonselected items resulted specifically from a prior instance of selective refreshing. Although the source of the negative impact was specific to prior refreshing, the negative consequence of refreshing was general to both subsequent reflective (Experiment 1 ) and subsequent perceptual (Experiment 2) processing of the nonrefreshed items. Additionally, this negative impact was observed even when the task was relatively simple (i.e., repeating) and RTs were relatively fast (as compared with refreshing or reading a new word). Again, this negative impact was not observed when participants read new items, suggesting that selective refreshing impairs subsequent access only to the items that are present at the time of refreshing and does not impair a subsequent cognitive event that involves a new item.

The finding of a negative impact of refreshing on repeating provides evidence that refreshing may be a mechanism by which reflective and perceptual processes interact. For example, Yi et al. (2008) demonstrated that refreshing a visual scene affects one's subsequent perception of the scene. After viewing a scene, participants refreshed the scene (refresh), were presented with the scene a second time (repeat), or were presented with a new scene. Later in the session, Yi et al. measured neural activity when participants were presented with the original scene again. They found repetition attenuation (i.e., reduced activity for repeated vs. novel scenes) for refreshed as well as for repeated scenes in the parahippocampal place area, a region that is known to be activated when scenes are perceived (Epstein \& Kanwisher, 1998). Briefly thinking of a visual stimulus thus had a facilitatory effect that was similar to perceiving the stimulus a second time. In contrast with the facilitatory effect of refreshing on subsequent percep- tion of the selected item in the Yi et al. study, the present data demonstrate a negative impact of refreshing on the subsequent perception of the nonselected items. It would be interesting to further explore whether the nature of this interaction (i.e., positive vs. negative) depends upon whether the selected or nonselected items are the focus of subsequent perception.

Despite the pattern of data in Experiment 2 and the outcome of the planned contrasts, the failure of the Task $2 \times$ Task 1 interaction to reach significance suggests the need for caution in interpreting these results as evidence that selective refreshing can negatively influence subsequent perceptual processing of the nonselected items. Instead, we might conclude from the main effect of Task 1 that prior refreshing generally slows subsequent perceptual processing regardless of whether this processing involves a new or a previously seen item. If so, this negative impact on subsequent repeating might reflect an RT cost in switching between process "type" (i.e., reflective to perceptual) from Task 1 to Task 2. In other words, RTs for performing a perceptual process on Task 2 (i.e., repeating an item, reading a new item) may be slower if one has just performed a reflective task (i.e., refreshing) on Task 1 than if one has just performed a perceptual task (i.e., repeating an item) on Task 1. Further work is needed to determine the relative contributions of a general reflective-to-perceptual switch cost versus a specific cost from refreshing that disadvantages perceptual processing of nonrefreshed items.

\section{GENERAL DISCUSSION}

Refreshing from a related three-word set, as compared with reading one of the items again, slowed RTs for subsequently refreshing a previously nonselected item from the set; hence, simply thinking of one particular item from, or one aspect of, an event may make it more difficult to think of other aspects of the experience. This difficulty does not appear to arise from inhibition of the previously nonrefreshed items, since older adults, who have shown deficits in inhibition in other tasks (Hamm \& Hasher, 1992; Tipper, 1991), did not show less of a negative impact of refreshing and, in fact, showed a greater negative effect.

If, as we propose, this negative impact of refreshing results from enhanced activation of the refreshed item, this suggests that reading a word a second time does not increase its activation to the same degree as does briefly thinking of the word. This is consistent with previous findings that long-term recognition memory is greater for items that have been refreshed than for those that have been repeated (Johnson et al., 2002). Presumably, refreshing increases and/or prolongs the activation of the word's representation, which in turn results in more successful encoding of the item. Increasing the representation's activation in and of itself may result in a stronger memory trace. Alternatively, or perhaps additionally, foregrounding or privileging the activation of the refresh target may make the item more accessible to other cognitive processes (e.g., noting relationships to other items or binding an item representation to contextual information; Chalfonte \& Johnson, 1996) that are involved during encoding. If 
refreshing is less efficient, this may affect what information is available to other cognitive processes. For example, assume that refreshing the Task 1 target strengthens the binding of this item to its location (or temporal order) and that the better bound the Task 1 target is, the easier it is to select "against" it (i.e., select the Task 2 target) on the basis of context cues. If so, less efficient refreshing in aging could contribute to a binding deficit that could, in turn, contribute to the greater negative impact of refreshing on subsequent refreshing that was observed in the present study.

If the function of refreshing is to privilege a target representation, it may be maximally necessary when the target item is not the most active representation that is available. For example, salient information is often better remembered on a later memory task (e.g., emotional information; Bloise \& Johnson, 2007; Bradley, Greenwald, Petry, \& Lang, 1992; Ochsner, 2000), perhaps because it is the most highly active representation when initially experienced. As a result, perceptual processing of salient items may result in sufficient activation of these representations for successful encoding. Less salient items may require refreshing to increase their accessibility to encoding processes. Refreshing becomes most critical when the to-be-remembered item occurs in the presence of competing items of higher activation levels, as a result of either salience (e.g., emotional; Johnson, Mitchell, Raye, McGuire, \& Sanislow, 2006) or converging associates (e.g., from semantic relatedness). One reason that older adults have difficulties in working memory tasks (Hasher \& Zacks, 1988; Hedden \& Park, 2001) may be that they have an impaired ability to privilege less active items.

Although refreshing may privilege a target item, it also results in reduced accessibility of the nonselected items. This negative impact of prior refreshing has implications for the use of whole report measures to characterize the limits of working memory, especially when items are semantically related. Partial report measures suggest that more items may be active than is reflected by whole report measures (Sperling, 1960). The results of the present study suggest that every selective event enhances the activation of the selected item, thereby reducing the relative accessibility of the nonselected items (a type of output interference; McGeoch, 1936; Tulving \& Arbuckle, 1963). This would result in lower estimates from whole report measures that require repeated selection from an active set.

The negative impact of selective refreshing is, on the face of it, similar to retrieval-induced forgetting (RIF) that has been demonstrated in long-term memory. For example, Anderson et al. (1994) presented participants with a list of study words from different semantic categories. After study, participants were repeatedly cued to retrieve some (but not all) of the study items from a given semantic category (i.e., the practiced category). During a later test session, participants were tested on their memory for all of the original study items. Memory for the items from the practiced category that were not recalled during the practice session was poorer than memory for items from an unpracticed category. Anderson and colleagues proposed that, during the practice trials, interference from these related items from the practice category was resolved by inhibition that then impaired later retrieval of these items.

Similarly, Blaxton and Neely (1983) proposed that inhibition resulting from repeated semantic retrieval can impair subsequent semantic retrieval. They used a category-generation task in which participants generated an exemplar in response to a category name and exemplar letter cue. For the generate-generate condition, participants generated either one or four exemplar primes from a semantic category before generating a target exemplar. In the read-generate condition, participants read either one or four exemplar primes before generating the target exemplar. The target exemplar was either semantically related or semantically unrelated to the prime exemplars. In the four-prime case, RTs for generating a related target exemplar were faster than those for generating an unrelated target exemplar in the read-generate condition, but not in the generategenerate condition. Blaxton and Neely suggested that during each instance of prime generation, multiple exemplars were covertly activated and subsequently inhibited as part of the generation process; hence, this retrieval-induced semantic inhibition accounted for the elimination of facilitation in the generate-generate condition. Consistent with this inhibition hypothesis, RTs for generating the target exemplar were significantly slower when the participant had just generated four primes versus when the participant had generated one prime, but only for related targets.

Common to the present study and the RIF paradigms that are described above (Anderson et al., 1994; Blaxton \& Neely, 1983), impairment of nonselected items depends on prior reflective, but not perceptual, processing of the items. Anderson et al. found impairment following multiple recalls, but not multiple study presentations, of the study items (see also Anderson, 2003), whereas priming in the Blaxton and Neely task was eliminated by prior generation, but not by prior reading, of exemplar primes. Similarly, in the present study, RTs for refreshing on Task 2 were slower following prior refreshing, but not following prior repeating.

In the present study, impairment was observed after a single selective refresh, suggesting that a single instance of even the simplest of reflective processes (i.e., refreshing) can result in an immediate reduction in the accessibility of nonselected items. This relative inaccessibility may not last beyond a couple of seconds once the selected item is no longer foregrounded (a testable question). That a single refresh was sufficient to induce impairment in the present task contrasts with RIF that has been observed in long-term memory. The standard RIF paradigm includes from 1 to up to 20 repeated retrieval events in the practice session, with a practice of 1 often being insufficient to result in impairment (Shivde \& Anderson, 2001). Similarly, in contrast with generating four exemplars, generating one exemplar resulted in facilitation and not inhibition in the Blaxton and Neely (1983) task. For RIF to occur in long-term memory, inhibition resulting from competition resolution might need to build up over multiple retrieval acts.

Anderson et al. (1994; see also Anderson, 2003) proposed that the amount of RIF that is observed is influenced by the amount of interference that is present dur- 
ing practice. Our finding of a larger negative impact of refreshing on related than on unrelated trials is consistent with the idea that refresh-induced inaccessibility is influenced by the level of competition. We observed a larger negative impact of refreshing on subsequent refreshing in OAs than in YAs, however, which - given evidence of inhibitory deficits associated with aging (Hasher et al., 2007) — argues against the idea that the negative impact reflects inhibition of the nonselected item. A reasonable alternative to that argument is that refreshing enhances the activation of the item, making it a stronger competitor when a previously nonselected item becomes the target. Although inhibition may better account for RIF, an enhanced-activation account appears to better explain refresh-induced inaccessibility.

The possibility that refreshing and retrieving (whether episodic or semantic) may resolve competition in somewhat different ways could reflect interesting differences in the characteristic dynamics of refreshing and retrieving. For example, during our refresh task, the competing information had just been explicitly processed perceptually and was, presumably, currently in an active state, whereas during retrieval practice (Anderson et al., 1994) or exemplar generation (Blaxton \& Neely, 1983) tasks, the competing information is presumably not currently active and is incidentally and/or implicitly activated. It seems reasonable that processes that operate on active information versus processes that operate to revive inactive information might differ in how they resolve competition. During online processing, it may become necessary to foreground one particular item from a set of currently active items in accordance with a momentary goal. Because the nonselected items may also be task relevant, however, it may be desirable for the activation of these items to remain above threshold. Enhancing the activation of the target item (via refreshing) makes it more accessible than the nontarget items yet allows the activations of the nontarget items to remain above threshold. During retrieval from long-term memory, items that are currently inactive are activated in response to a cue. Nontarget items that are incorrectly or inadvertently activated or reactivated will compete for selection. In contrast with the online case, these distractor items are less likely to be necessary, and their continued activation may, in fact, be disruptive to consolidation of the target information. In such cases, repeated retrieval of the target item in conjunction with repeated inhibition of distracting information may help episodic memories become consolidated.

\section{AUTHOR NOTE}

This research was supported by Grants AG15793 and AG09253 from the National Institute on Aging to M.K.J. and by a National Science Foundation Graduate Research Fellowship to J.A.H. We thank Michael Anderson, Mara Mather, James Neely, and two anonymous reviewers for useful comments on earlier drafts of this article. We are grateful to Rachel Eaton and Caroline Huron for their contributions to the pilot data that inspired the present study. We also thank Kristen Pring-Mill, Sharen McKay, and Cara Watts for assistance with data collection and coding, and Hillary Frankel, Jessica Jacobson, Jeffrey Tai, and Shannon Tubridy for assistance with data scoring. Correspondence concerning this article should be addressed to J. A. Higgins, P.O. Box 208205, New Haven, CT 06520-8205 (e-mail: julie.higgins@yale.edu).

\section{REFERENCES}

Anderson, M. C. (2003). Rethinking interference theory: Executive control and the mechanisms of forgetting. Journal of Memory \& Language, 49, 415-445.

Anderson, M. C., BJork, R. A., \& BJork, E. L. (1994). Remembering can cause forgetting: Retrieval dynamics in long-term memory. Journal of Experimental Psychology: Learning, Memory, \& Cognition, 20, 1063-1087.

BADDELeY, A. D. (1986). Working memory. New York: Oxford University Press.

BadDeley, A. D., \& Hitch, G. (1974). Working memory. In G. H. Bower (Ed.), The psychology of learning and motivation: Advances in research and theory (Vol. 8, pp. 47-89). New York: Academic Press.

Battig, W. F., \& Montague, W. E. (1969). Category norms for verbal items in 56 categories: A replication and extension of the Connecticut category norms. Journal of Experimental Psychology, 80, 1-46.

BJORK, R. A. (1978). The updating of human memory. In G. H. Bower (Ed.), The psychology of learning and motivation: Advances in research and theory (Vol. 12, pp. 235-259). New York: Academic Press.

Blaxton, T. A., \& Neely, J. H. (1983). Inhibition from semantically related primes: Evidence of a category-specific inhibition. Memory \& Cognition, 11, 500-510.

Bloise, S. M., \& Johnson, M. K. (2007). Memory for emotional and neutral information: Gender and individual differences in emotional sensitivity. Memory, 15, 192-204.

Blumenfeld, R. S., \& RANGanath, C. (2006). Dorsolateral prefrontal cortex promotes long-term memory formation through its role in working memory organization. Journal of Neuroscience, 26, 916-925.

Botvinick, M., Nystrom, L. E., Fissell, K., Carter, C. S., \& Cohen, J. D. (1999). Conflict monitoring versus selection-for-action in anterior cingulate cortex. Nature, 402, 179-181.

Bradley, M. M., Greenwald, M. K., Petry, M. C., \& Lang, P. J. (1992). Remembering pictures: Pleasure and arousal in memory. Journal of Experimental Psychology: Learning, Memory, \& Cognition, 18, 379-390.

Chalfonte, B. L., \& Johnson, M. K. (1996). Feature memory and binding in young and older adults. Memory \& Cognition, 24, 403416.

Collins, A. M., \& Loftus, E. F. (1975). A spreading-activation theory of semantic processing. Psychological Review, 82, 407-428.

Cowan, N. (1999). An embedded-processes model of working memory. In A. Miyake \& P. Shah (Eds.), Models of working memory: Mechanisms of active maintenance and executive control (pp. 62-101). Cambridge: Cambridge University Press.

D’Esposito, M., Aguirre, G. K., Zarahn, E., Ballard, D., Shin, R. K., \& LEASE, J. (1998). Functional MRI studies of spatial and nonspatial working memory. Cognitive Brain Research, 7, 1-13.

EPSTEIN, R., \& KANWISHER, N. (1998). A cortical representation of the local visual environment. Nature, 392, 598-601.

Folstein, M. F., Folstein, S. E., \& McHugh, P. R. (1975). Mini-mental state: A practical method for grading the cognitive state of patients for the clinician. Journal of Psychiatric Research, 12, 189-198.

Hamm, V. P., \& Hasher, L. (1992). Age and the availability of inferences. Psychology \& Aging, 7, 56-64.

HASHER, L., LUSTIG, C., \& ZACKs, R. T. (2007). Inhibitory mechanisms and the control of attention. In A. Conway, C. Jarrold, M. Kane, A. Miyake, \& J. Towse (Eds.), Variation in working memory (pp. 227-249). New York: Oxford University Press.

HASHER, L., \& ZACKS, R. T. (1988). Working memory, comprehension, and aging: A review and a new view. In G. H. Bower (Ed.), The psychology of learning and motivation: Advances in research and theory (Vol. 22, pp. 193-225). San Diego: Academic Press.

HedDEN, T., \& PARK, D. (2001). Aging and interference in verbal working memory. Psychology \& Aging, 16, 666-681.

JoHnson, M. K. (1992). MEM: Mechanisms of recollection. Journal of Cognitive Neuroscience, 4, 268-280.

Johnson, M. K., \& HiRST, W. (1993). MEM: Memory subsystems as processes. In A. F. Collins, S. E. Gathercole, M. A. Conway, \& P. E. Morris (Eds.), Theories of memory (pp. 241-286). Hove, U.K.: Erlbaum. 
Johnson, M. K., Mitchell, K. J., Raye, C. L., McGuire, J. T., \& SANISLOW, C. A. (2006). Mental rubbernecking to negative information depends on task context. Psychonomic Bulletin \& Review, 13, 614-618.

Johnson, M. K., Raye, C. L., Mitchell, K. J., Greene, E. J., \& ANDERSON, A. W. (2003). fMRI evidence for an organization of prefrontal cortex by both type of process and type of information. Cerebral Cortex, 13, 265-273.

Johnson, M. K., Raye, C. L., Mitchell, K. J., Greene, E. J., CunNINGHAM, W. A., \& SANisLow, C. A. (2005). Using fMRI to investigate a component process of reflection: Prefrontal correlates of refreshing a just-activated representation. Cognitive, Affective, \& Behavioral Neuroscience, 5, 339-361.

Johnson, M. K., Reeder, J. A., Raye, C. L., \& Mitchell, K. J. (2002). Second thoughts versus second looks: An age-related deficit in reflectively refreshing just-activated information. Psychological Science, 13, 64-67.

KuČERA, H., \& FRANCIS, W. N. (1967). Computational analysis of presentday American English. Providence, RI: Brown University Press.

LofTus, E. F. (1973). Activation of semantic memory. American Journal of Psychology, 86, 331-337.

McGeOch, J. A. (1936). Studies in retroactive inhibition: VII. Retroactive inhibition as a function of the length and frequency of presentation of the interpolated lists. Journal of Experimental Psychology, 19, 674-693.

McGEOCH, J. A. (1942). The psychology of human learning: An introduction. New York: Longmans.

Morris, N., \& Jones, D. M. (1990). Memory updating in working memory: The role of the central executive. British Journal of Psychology, 81, 111-121.

Oberauer, K., \& KLIEGL, R. (2006). A formal model of capacity limits in working memory. Journal of Memory \& Language, 55, 601-626.

OCHSNER, K. N. (2000). Are affective events richly recollected or simply familiar? The experience and process of recognizing feelings past. Journal of Experimental Psychology: General, 129, 242-261.

Raye, C. L., Johnson, M. K., Mitchell, K. J., Greene, E. J., \& JohnSON, M. R. (2007). Refreshing: A minimal executive function. Cortex 43, $135-145$.

Raye, C. L., Mitchell, K. J., Reeder, J. A., Greene, E. J., \& JohnSON, M. K. (2008). Refreshing one of several active representations Behavioral and functional magnetic resonance imaging differences between young and older adults. Journal of Cognitive Neuroscience, 20, 852-862.

Roth, J. K., \& Courtney, S. M. (2007). Neural system for updating object working memory from different sources: Sensory stimuli or long-term memory. NeuroImage, 38, 617-630.

Shapiro, S. I., \& Palermo, D. S. (1970). Conceptual organization and class membership: Normative data for representatives of 100 categories. Psychonomic Monograph Supplements, 3, 107-127.

ShIvde, G., \& ANDERSON, M. C. (2001). The role of inhibition in meaning selection: Insights from retrieval-induced forgetting. In D. S. Gorfein (Ed.), On the consequences of meaning selection: Perspectives on resolving lexical ambiguity (pp. 175-190). Washington, DC: American Psychological Association.

Smith, E. E., Shoben, E. J., \& RIPS, L. J. (1974). Structure and process in semantic memory: A featural model for semantic decisions. Psychological Review, 81, 214-241.

SPERLING, G. (1960). The information available in brief visual presentations. Psychological Monographs: General \& Applied, 74, 1-29.

SternberG, S. (1966). High-speed scanning in human memory. Science, 153, 652-654.

TIPPER, S. P. (1991). Less attentional selectivity as a result of declining inhibition in older adults. Bulletin of the Psychonomic Society, 29, 45-47.

Tulving, E., \& Arbuckle, T. Y. (1963). Sources of intratrial interference in immediate recall of paired associates. Journal of Verbal Learning \& Verbal Behavior, 1, 321-334.

WECHSLER, D. (1987). Manual for the Wechsler Adult Intelligence ScaleRevised. New York: Psychological Corporation.

Yi, D., Turk-Browne, N. B., Chun, M. M., \& Johnson, M. K. (2008). When a thought equals a look: Refreshing enhances perceptual memory. Journal of Cognitive Neuroscience, 20, 1371-1380.

\section{NOTES}

1. Statistical analyses on RTs for refreshing or repeating a word on Task 1 showed a significant main effect of Task $1[F(1,76)=229.17$, $\left.M S_{\mathrm{e}}=5,542.16, \eta_{\mathrm{p}}^{2}=.75\right]$ and a significant age $\times$ Task $1[F(1,76)=$ $\left.7.52, M S_{\mathrm{e}}=5,542.16, \eta_{\mathrm{p}}^{2}=.09\right]$ interaction. Although both age groups were slower to refresh than to repeat, this increase was significantly greater in OAs (refresh $=869 \mathrm{msec}$; repeat $=706 \mathrm{msec}$ ) than in YAs (refresh $=694 \mathrm{msec}$; repeat $=581 \mathrm{msec})$, replicating the findings of Johnson et al. (2002). The main effect of semantic relatedness was not significant (unrelated $=714 \mathrm{msec}$, related $=712 \mathrm{msec}$ ) $[F(1,76)=0.24$, $\left.M S_{\mathrm{e}}=1,015.89, p=.62\right]$, and semantic relatedness did not interact significantly with any of the other factors.

2 . Although the age $\times$ Task $2 \times$ Task $1 \times$ semantic relatedness interaction was not significant, as can be seen in Table 1, an increase in RTs as a result of prior refreshing was observed on both related and unrelated trials for OAs, but only on related trials for YAs. This observation was supported by one-sample $t$ tests on the mean increase in RTs on Task 2 when participants had just refreshed versus when they had just repeated (i.e., refresh-refresh minus repeat-refresh and refresh-read minus repeat-read) on related and unrelated trials for each age group. For YAs, the mean increase was significantly different from zero for related trials [28 msec; $t(53)=2.62$, Cohen's $d=0.36$ ] but not for unrelated trials $[1 \mathrm{msec} ; t(53)=0.044, p=.96]$. In contrast, the increase for OAs was significantly different from zero for both related trials [96 msec; $t(23)=$ 3.95 , Cohen's $d=0.81]$ and unrelated trials [66 msec; $t(23)=3.08$, Cohen's $d=0.63]$, and it was numerically larger for related trials. This pattern of data suggests that a negative impact of refreshing may be observed at lower levels of competition in OAs than in YAs.

3. As in Experiment 1, statistical analyses on RTs for refreshing or repeating on Task 1 showed slower RTs for refreshing $(783 \mathrm{msec})$ than for repeating $(597 \mathrm{msec})\left[F(1,15)=86.03, M S_{\mathrm{e}}=6,451.53, \eta_{\mathrm{p}}^{2}=.85\right]$. The main effect of semantic relatedness was not significant [unrelated = $689 \mathrm{msec}$; related $=690 \mathrm{msec} ; F(1,15)=0.004, M S_{\mathrm{e}}=900.00, p=$ .95], and semantic relatedness did not interact with Task $1[F(1,15)=$ $\left.0.97, M S_{\mathrm{e}}=1,242.36, p=.34\right]$. 


\section{APPENDIX}

Influence of Exemplar Rank on the Negative Impact of Refreshing in Experiment 1

Related word sets were constructed in such a way that there was one high-, one medium-, and one low-ranking exemplar from a semantic category. Given that high-ranking exemplars have more overlapping features with other exemplars, and with the category more generally, than do low-ranking exemplars (Collins \& Loftus, 1975; Smith, Shoben, \& Rips, 1974), high-ranking items should be the most active and low-ranking items the least active representations within the context of this paradigm. According to an inhibition account, the more competition that an item provides, the more inhibition that is needed (Anderson et al., 1994). Because of their higher state of activation within a related set, higher ranked exemplars should provide the most competition when they are distractors on Task 1, require the most inhibition, and thus have the lowest accessibility as Task 2 targets. An inhibition account thus predicts that a larger increase in RTs as a result of prior refreshing will occur when the rank of the Task 1 target is lower than that of the Task 2 target (low-high trials) versus when the rank of the Task 1 target is higher than that of the Task 2 target (high-low trials).

\section{Results}

Mean increases to refresh on Task 2 when participants had just refreshed on Task 1 versus when they had just repeated on Task 1, depending on rank combination (high-low and low-high), in Experiment 1 are presented in Table A1. Collapsed across both age groups, this mean increase was significantly greater for related high-low trials $(63 \mathrm{msec})$ than for unrelated high-low trials $(20 \mathrm{msec})[t(77)=2.25$, Cohen's $d=0.25]$, but did not differ across relatedness for low-high trials. The mean increase for related trials was $31 \mathrm{msec}$, and the mean increase for unrelated trials was $18 \mathrm{msec}[t(77)=0.70, p=.49]$.

\section{Discussion}

If the negative impact of prior refreshing on the nonselected items resulted from these items being inhibited, this effect should be most pronounced on low-high trials. The present results are not consistent with this hypothesis. The negative impact that resulted from prior refreshing for related as compared with unrelated items was significant on high-low but not on low-high trials. Although preliminary, the results of the rank analysis, taken together with the larger negative impact of refreshing that was observed in OAs than in YAs in Experiment 1, provide converging evidence that the negative impact of refreshing is not due to inhibition of the nonrefreshed items.

Instead, these results are more consistent with the hypothesis that reduced accessibility results from enhanced activation of the refreshed item and not from inhibition of the nonrefreshed items. As a result of being refreshed on Task 1, the mental representation of the Task 1 target was more highly activated - particularly if this item was highly activated initially, (i.e., a high-ranking exemplar) — and consequently was a particularly strong competitor during selective refreshing on Task 2 (when it became a nontarget item). This highly activated Task 1 target may "block" (McGeoch, 1942) access to the more weakly activated Task 2 target. Additional time may be needed to resolve response conflict between the new target item and the previously refreshed target — that is, to select a less active target in the presence of a more active competitor.

Table A1

Impact of Task 1 Refreshing on Response Times for Refreshing on Task 2 As a Function of Rank Combination in Experiment 1

\begin{tabular}{|c|c|c|c|c|}
\hline & \multicolumn{2}{|c|}{ High-Low } & \multicolumn{2}{|c|}{ Low-High } \\
\hline & $\begin{array}{c}\text { Mean } \\
\text { Increase }\end{array}$ & $95 \% \mathrm{CI}$ & $\begin{array}{c}\text { Mean } \\
\text { Increase }\end{array}$ & $95 \% \mathrm{CI}$ \\
\hline \multicolumn{5}{|l|}{ Young Adults } \\
\hline Unrelated & -4 & $-38,29$ & -2 & $-32,27$ \\
\hline Related & 43 & 12,74 & 11 & $-19,41$ \\
\hline \multicolumn{5}{|l|}{ Older Adults } \\
\hline Unrelated & 75 & 21,128 & 63 & $-18,143$ \\
\hline Related & 107 & 45,170 & 78 & 0,155 \\
\hline
\end{tabular}

Note-Scores represent mean increase (and confidence interval of the mean increase) in milliseconds in Task 2 RTs for refreshing (i.e., RTs for refreshing on Task 2 when participants have just refreshed on Task 1 minus RTs for refreshing on Task 2 when they have just repeated on Task 1). The pattern of data is inconsistent with an inhibition account, which would predict that the largest mean increase would occur on low-high trials. High-low trials are those in which the Task 1 target was a higher ranking exemplar and the Task 2 target was a lower ranking exemplar. Low-high trials are those in which the Task 1 target was a lower ranking exemplar and the Task 2 target was a higher ranking exemplar. 